\title{
Mapping Vertical Urban Growth in Mexico City in a Seismic Risk Context
}

\author{
Milton Montejano-Castillo*, Mildred Moreno-Villanueva, Erick Espinosa-Jiménez \\ Escuela Superior de Ingeniería y Arquitectura Unidad Tecamachalco, Instituto Politécnico Nacional, Av. Fuente de los Leones \\ 28, CP 53950, Naucalpan, Estado de México, México
}

Corresponding Author Email: mmontejanoc@ipn.mx

https://doi.org/10.18280/ijsse.100113

Received: 17 June 2019

Accepted: 14 February 2020

\section{Keywords:}

disasters, earthquake, high-rise buildings, seismic risk, urban corridors, urban form, vertical urban growth

\begin{abstract}
Due to the physical phenomenon known as resonance, the damages caused by the earthquakes of 1985 and 2017 in Mexico City have been strongly related to the number of storeys of collapsed buildings given the lacustrine nature of this territory. In spite of the apparent relationship between location, land value, building investment, urban planning and seismic risk, there has not been an attempt to correlate these variables to continue understanding the vulnerability of this city, and the way in which certain cadastral and urban planning instruments have been eventually increasing the risk. Therefore, this work correlate and map the mentioned variables and their changes in a period time from 2002 to 2012. Considering urban corridors as the sample, the results show that building codes, planning instruments and real estate trends have been implemented in a contradictory way. One the one hand, seismic zoning has been more precise in time. On the other hand, urban planning and real estate investments have been promoting densification in unstable soil. Therefore, future formulation of urban policies should be in consonance to seismic zones, without forgetting that seismic zoning and vertical growth are not a static phenomenon but a continuous one.
\end{abstract}

\section{INTRODUCTION}

Urban growth of cities regularly occurs in a diverse manner, and in their development, attempts are made to take into account most of the aspects that intervene in their growth, the needs of the inhabitants, the historical stage, the trends that are developed internationally, aspects of sustainability, cultural aspects, and the economic and political dimensions that may even be of convenience for elite groups, or sometimes the city has to be rebuilt according to unforeseen events such as natural phenomena that cause disasters.

As a consequence of the above and not being clear if the best for development are compact cities or not [1], the failure to establish a definitive discourse of what would be the best way to plan the city due to its complexity in urban agglomerations such as Mexico City, this ambiguity has been generating an uneven vertical growth in the city, which raises the interest to study the verticality of the city related to other phenomena that are considered inseparable by promoting this type of growth and that present serious problems at a certain moment.

On the one hand, by promoting verticalization, we have the idea of desired effects such as: 1 . That with vertical urban growth there may be a decrease in displacements and therefore energy savings, more organized mobility, and a reduction in carbon emissions derived from the reduction of trips in private vehicles or public transport; 2 . That with vertical urban growth there may be a more rational use of land as well as infrastructure and equipment, concentration of services and accessibility for all; or 3 . That vertical growth can create access to social housing in the centrality and thereby reduce costs for the beneficiaries.
On the other hand, there are the undesired effects of verticalization, which may be related to certain risks such as: 1. Excessive density in places that were not planned in its infrastructure because they are part of the oldest areas of the city that come to collapse in their networks of drainage, water or transport by the increase in their verticality and density of inhabitants; 2. That real estate speculation may cause segregation and fragmentation due to the increase in the cost of land and services, or the indiscriminated use of the territory; or 3. That an indiscriminated verticalization can occur in areas of risk leading the city to disaster, events that even expose corruption in the implementation of planning instruments. Therefore, in this research, the recent context of verticalization in Mexico City at important moments of change is taken for study. The earthquake that occurred in Mexico in 2017 left the capital city again with the urgency of rethinking the processes that affected a vertical urbanization, to be taken into account in the reconstruction. This event reopened the discussion about vertical urban growth: is a vertical city better? How to do it and where? At what heights, considering that there is an association between the damages left by the earthquake in a certain range of levels? What is the situation of verticalization in Mexico City? And what has been the relationship between urban planning, the real estate market and the process of verticalization?

Therefore, this work aims to identify areas according to their height ranges through the identification of corridors of low, medium and high density; Another of the objectives is to know some of the effects of verticalization in Mexico City in the XXI century in terms of verticalization and age of the city, creation of new high-rise areas ("spontaneous verticalization") and the relationship between verticalization and seismic risk. 


\section{MEXICO CITY: BETWEEN DISASTERS AND URBAN PLANNING}

Urban development in Mexico City in the XX century was shaped by a process of growth, consolidation and destruction. Such processes led this city to a reconfiguration in a rapid and improvised way as shown in Figure 1.

Seismic zoning has not been a static factor but it has been more precise after each disaster (1957, 1985 and 2017 so far). Additional to this precisions, urban planning has shaped the central zones of the city creating densification and verticalization in the most vulnerable parts.

Before 1985, the promotion of verticality was speculated in urban corridors in the Urban Development Plan to unite centers and subcenters of economic activity and high densities; However, after the earthquake of 1985, the vertical growth of the city and the guidelines that governed it were rethought, and the idea of verticalizing the city due to the fear of a disaster with even greater damages was left aside.

During the uncertainty of safety in the city, there was a depopulation from the centrality that generated displacements to the peripheries, which in turn generated consequences of another nature such as increased long journeys, sealing of surfaces of permeable areas, or the construction of intraurban roads, among others.

At the beginning of the 21 st century, as another stage, the idea of redensifying the city came back and the government tried to repopulate the central areas, which gave rise to the creation of criteria such as the "Guide for the redensification" [2] and public policies, first with the policy of Bando 2 and later the norm 26 with the greatest impact on the verticalization of the city, which occurred irregularly despite the rules, and arbitrarily without taking into account risk areas.

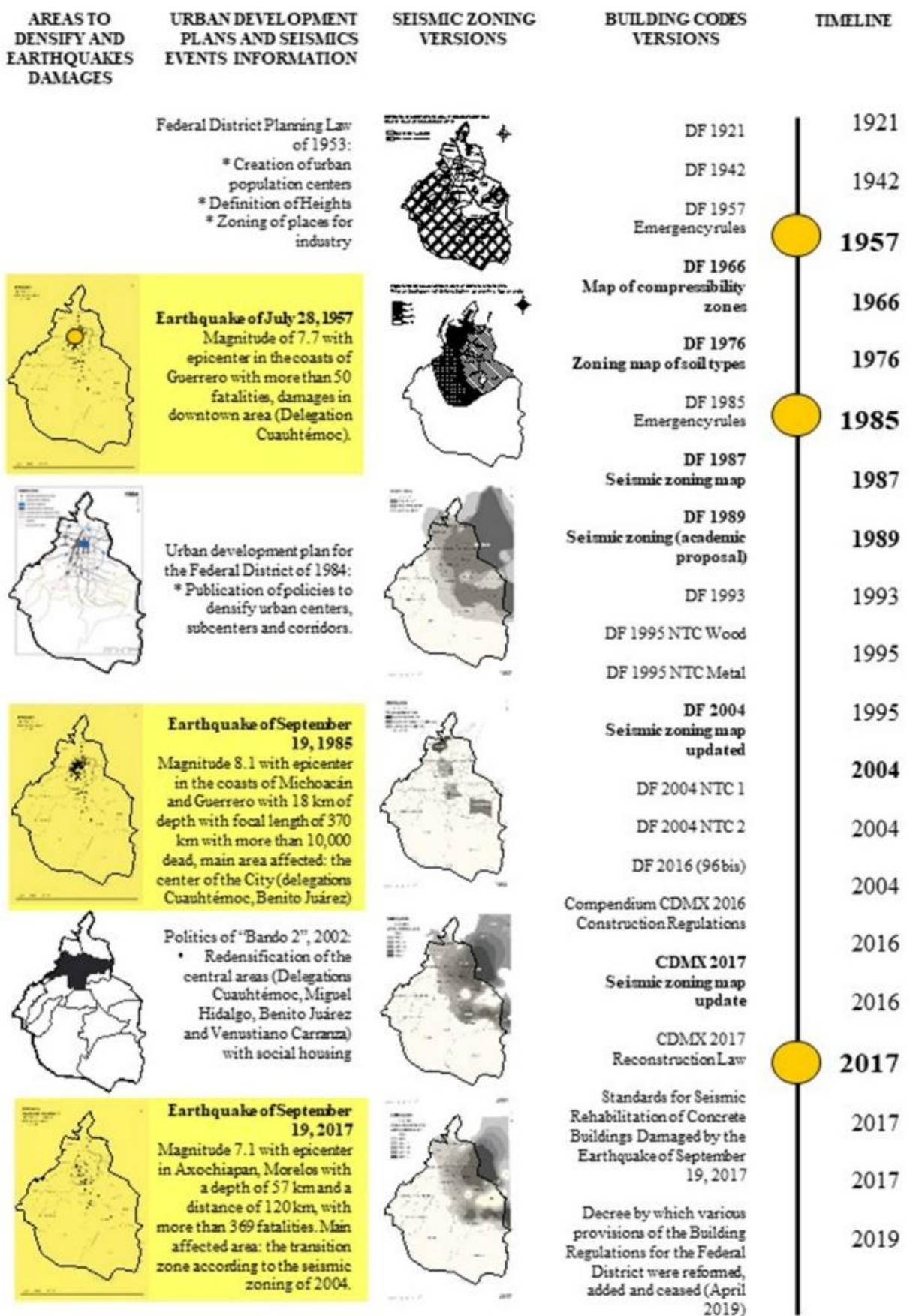

Figure 1. Evolution of urban development plans and building codes for Mexico City according to past earthquakes. (Source: own elaboration based on smie.org.mx) 
The critical importance of the relation between height and risk goes back to the 1980's. After the earthquake of 1985 a group of physical scientists observed that the seismic waves were magnified by a natural phenomenon known as resonance. Resonance occurs when the period of the seismic wave coincides with the period of oscillation of the buildings, that is to say, the time for the building elapsed to return to the same point, like a pendulum. If the period of oscillation of the wave is long (originated at a far distance), the period may coincides with the oscillation of tall buildings, contrary case if the epicenter locates closer to the city, so that the period of the wave is shorter, affecting smaller buildings, as has been corroborated in 1985 and 2017 (see Tables 1 and 2). As a consequence, building codes were then modified and a new seismic zoning was proposed based on three zones: the zone of the lake, the zone of transition and the zone of solid soil (see Figure 1). However, buildings constructed before each building code-updating, will be possibly at risk. In other words, uncertainty factor will be always present (see Table 3).

Table 1. Characteristics of earthquakes of 1985 and 2017. (Source: Meli, 2009 \& ISCDF, 2018)

\begin{tabular}{cccc}
\hline $\begin{array}{c}\text { Year of } \\
\text { earthquake }\end{array}$ & Magnitude & $\begin{array}{c}\text { Distance to epicentre / } \\
\text { Depth of epicentre }\end{array}$ & $\begin{array}{c}\text { Seismic area where most } \\
\text { collapses occurred }\end{array}$ \\
\hline 1985 / Sept 19 & 8.1 & $370 / 18 \mathrm{Km}$ & Zone of the lake \\
2017 / Sept 19 & 7.1 & $120 / 57 \mathrm{Km}$ & Zone of transition \\
\hline
\end{tabular}

Table 2. Percentage of collapsed or severely damaged buildings according to number of storeys in Mexico City after the earthquake of 1985 and 2017.

(Source: Meli, 2009 \& ISCDF, 2018)

\begin{tabular}{cccc}
\hline \multicolumn{2}{c}{1985 (zone of highest damage) } & \multicolumn{2}{c}{ 2017 (total amount of damaged buildings) } \\
\hline Height (storeys) & Number & Height (storeys) & Number / Percentage \\
\hline $1-2$ & 0.9 & $0-3$ & $526(46 \%)$ \\
$3-5$ & 1.3 & $4-6$ & $368(32 \%)$ \\
$6-8$ & 8.4 & $7-9$ & $161(14 \%)$ \\
$9-12$ & 13.6 & 10 and more & $80(7 \%)$ \\
12 and more & 10.5 & & \\
\hline
\end{tabular}

Table 3. Evolution of building codes in Mexico City according to Figure 1 (Own elaboration). $\mathrm{O}=$ mandatory

\begin{tabular}{cllccc}
\hline Year of construction & & \multicolumn{4}{c}{ Compliance to building codes } \\
\hline & $\mathbf{1 9 5 7}$ & $\mathbf{1 9 8 5}$ & $\mathbf{2 0 0 4}$ & $\mathbf{2 0 1 7}$ & $\mathbf{2 0 1 9}$ \\
& $\mathbf{1 9 6 6}$ & $\mathbf{1 9 8 7}$ & & & \\
\hline Before 1985 & $\mathrm{1976}$ & & & & \\
$\begin{array}{c}\text { Between 1986 and 2003 } \\
\text { Between 2005 and 2017 } \\
\text { After 2018 }\end{array}$ & & O & O & O & O \\
\hline
\end{tabular}

The study of vertical urban growth has been conducted with particular interest in Asian cities [3-7], with just a very few cases in Latin American urban agglomerations [8]. Nevertheless, studies that correlate high-rise buildings location to earthquakes effects are still very scarce. Availability of information and the inexistence of data for several years limit at large this type of studies.

Therefore, this article will focus in the first decades of this century taking into consideration the urban policies implemented from 2002 until 2012 that promoted vertical urban growth, currently under discussion as a consequence of the disaster of 2017.

\section{METHOD AND UNITS OF ANALYSIS}

In the previous section, the difficulty of obtaining information from different periods regarding height has already been mentioned. For this study, cadastral information was obtained for the year 2002 (collected in the field) and 2012 (from an official database), which opened the possibility of exploring the differences in terms of vertical urban growth. This study is based on a sampling and it takes the main avenues of Mexico City as units of analysis, such avenues are known as corridors of reference value. The total of these avenues is 136 with a total of 12,793 buildings for 2002 , and 21,335 buildings in 2012 (see Table 4).

Table 4. Total number of buildings of the sample according to number of storeys in Mexico City. (Source: Field survey for 2002 and official sources for 2012)

\begin{tabular}{ccccc}
\hline Number of storeys & $\mathbf{2 0 0 2}$ & $\mathbf{\%}$ & $\mathbf{2 0 1 2}$ & $\mathbf{\%}$ \\
\hline 1-2 storeys & 7,745 & 60.54 & 12,984 & 60.86 \\
3-5 storeys & 3,726 & 29.13 & 6,174 & 28.94 \\
6-10 storeys & 890 & 6.96 & 1,664 & 7.80 \\
11 storeys and more & 432 & 3.38 & 513 & 2.40 \\
Total & 12,793 & 100 & 21,335 & 100 \\
\hline
\end{tabular}

One of the premises for which the corridor is considered for this study is the assumption that it is on these avenues where the processes of verticalization of the city are observed with greater clarity. Corridors are defined as "a set of buildings that by the characteristics of use to which they are destined, mainly non-residential (such as commercial, industrial, services, offices, among others, and / or mixed -including housing-), and whose front or fronts adjoin a public avenue of the Federal District, has become a value corridor with greater economic 
activity and greater commercial value of the land with respect to the predominant one in the area" [9].

Each one of these corridors has a land reference value that is intended to serve as a reference unit value in the appraisal review and the determination of reference values for taxes on the acquisition of real estate and the cadastral values for the property tax [10]. These values "are the result of exhaustive research, analysis and weighting of the real estate market" [10], and like the urban corridor (for planning purposes), the value corridor is still one of the current cadastral instruments.

To make the height analysis, there were some observations referring to the relationship between heights and damages caused by the 1985 and 2017 earthquakes that occurred in Mexico City.

Taking into account that after 1985 the building regulations in Mexico City were modified, it was decided to analyze the height that corresponds to the appearance of vertical buildings with housing use promoted during the decade 2002-2012 (610 storeys).

Another reference was the current height ranges defined by the Secretariat of Finance of the Government of Mexico City, which correspond to: 1 to 2 floors; 3 to 5 floors; 6 to 10 floors; 11 to 15 floors; 16 to 20 floors, and 21 and more floors. However, when starting to analyze the information, it was observed that the last two ranges (16 to 20 and 21 and more floors), were statistically not significant, with percentages between 0.00 and $2.00 \%$, so it was decided to integrate the last three ranges in a single one, that is, as "buildings of more than 11 levels", with the following results.

\section{COMPOSITION AND CHANGES IN THE VERTICALITY OF MEXICO CITY}

Contrary to what was thought at the beginning of the study, or what is intuitively observed at the street level, the buildings located along the avenues (corridors), are not mostly high-rise buildings but rather very small buildings. The range of heights prevailing at the beginning of the century in Mexico City on corridors from 1 to 2 levels is the rank with the greatest quantitative weight with almost $60 \%$; the range from 3 to 5 levels follows with almost $30 \%$ (see Figures 2 and 3). With almost $7 \%$ the range from 6 to 10 levels is in third place and the rest with around $2 \%$ and less than $1 \%$ for the remaining ranges. These values do not present modifications in both periods.

Spatially, and due to the constant use of this hypothesis in reference studies, the center-periphery pattern was tested with the data of this study, making the summation of buildings located in concentric circles starting from the historic center of the city, which revealed certain tendencies.

Ordering the observations (percentages of buildings by rank) by their distance to the historic center of Mexico City, it is observed that for the range from 1 to 2 levels there is a tendency to grow as we move away from the city center (see Figures 2 and 3), which could indicate some "exclusion" of the smaller buildings from the main centrality, otherwise for the range of heights from 3 to 5 levels, which shows a tendency to increase as we approach the center of the city, that is to say, certain attraction towards the main centrality, while for the rest of the ranges there seems to be no determined location given by the historical centrality of the city, apparently it is a question of scattered verticality that possibly does not occur in contained polygons, but rather along avenues that concentrate economic activity and services, or in certain points of the city, which are better identified by looking at maps of increments of constructive density, as described in the following.

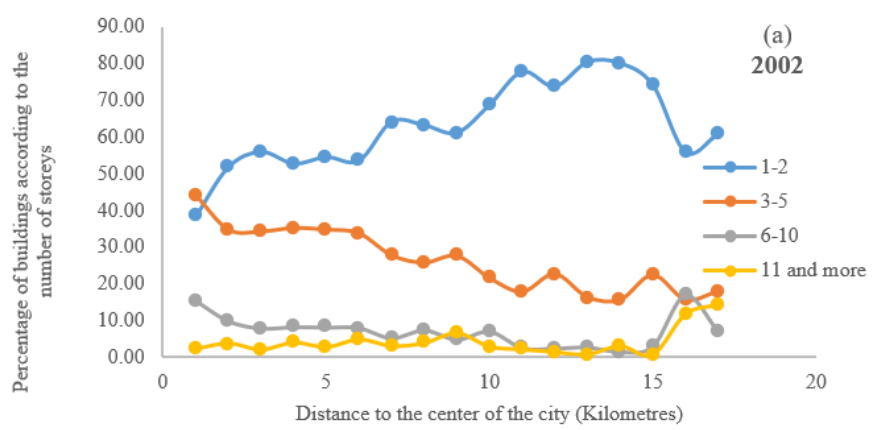

Figure 2. Number of storeys according to the distance to the center of Mexico City, 2002 (percentages). (Source: Field survey)

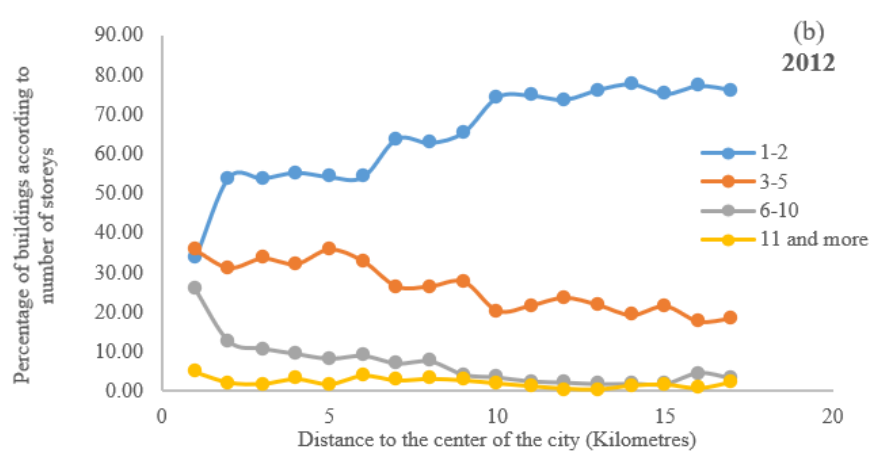

Figure 3. Number of storeys according to the distance to the center of Mexico City, 2012 (percentages). (Source: official sources)

\subsection{Indiscriminated verticalization in a city at seismic risk}

On September 19, 2017, an earthquake of magnitude 7.1 at 13:14 hours with epicenter in the states of Morelos and Puebla, caused severe damage in several cities of the Mexican Republic, Mexico City was one of the most affected areas, and there it was observed that indiscriminated verticalization in risk areas can cause disasters, since acts of corruption were exposed.

These are areas that are not necessarily very high areas but are places where rules are convenient for some actors, or the law is not followed. Here the study of verticalization helps to visualize latent areas of risk where measures must be taken before the next disaster strikes.

Derived from the policies that were formulated to redensify the city, and in spite of the fact that these measures were already repealed or suspended, this had already opened the way for other ways to be found to verticalize the city through the same territorial ordinance regulations in the city of Mexico in each one of the Municipalities. Examples of these cases are the "transfer of potential of urban development" that is used to increase the number of levels and the reduction of the free area when the project requires it.

An example of this is the building Bretaña 90 (see Figure 4), sold as new apartments when in fact they were not. This construction, which obtained its building permission in 1958 for a two-level dwelling, remained for four years with four levels, exceeding the initial permit until 2016. Later it was purchased by a construction company that increased two levels 
and restored the façade to promote it and offer it as if it were a new building, leaving a 6 -storey building that collapsed during the 2017 earthquake [11].

Examples like this let us see that the corruption with which the city was verticalized in the risk areas should be evaluated, as seen in the map (see Figure 5), where the buildings that suffered partial damage or total collapse (in green), were built in the last century and locate in an area at risk (IIID), while the buildings that were built in the XXI century (in blue), likewise locate at risk areas and on the corridors that grew with a high density speed or close to them.

This example also shows us that an "informal vertical growth" of the buildings may also occur in the "formal city" and not just in informal settlement areas, where this type of growth has become a characteristic feature of a permanent densification processes.

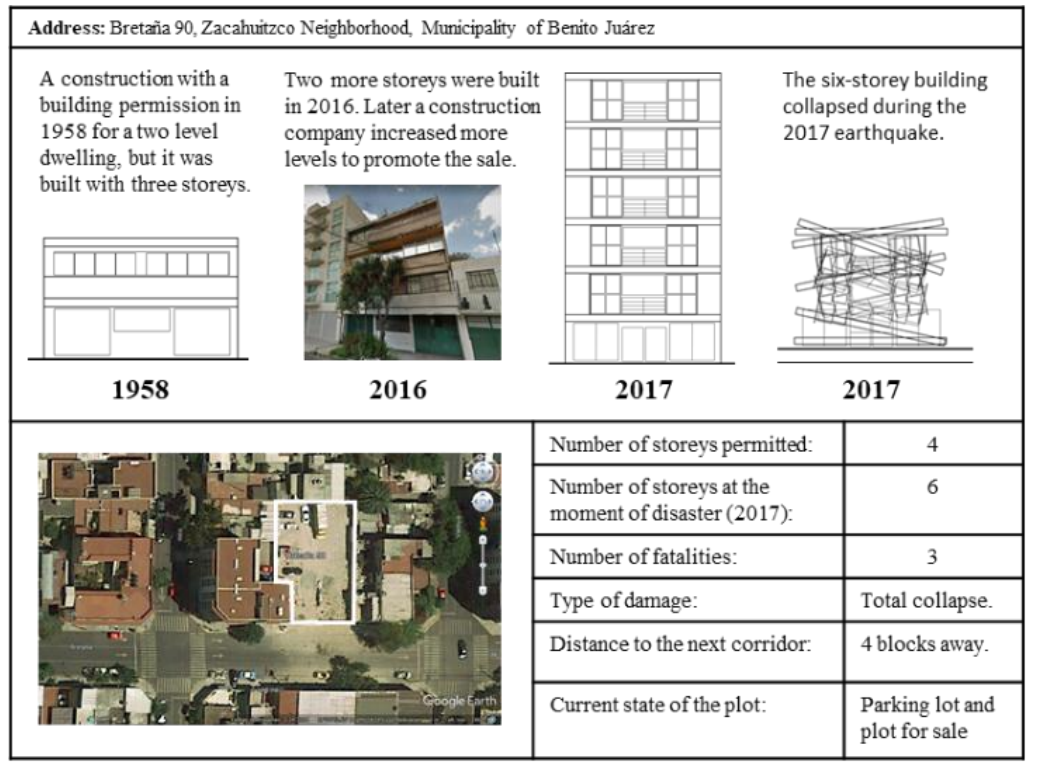

Figure 4. Bretaña 90, a building that collapsed in the earthquake of September 2017. (Source: own elaboration based on Google Maps and Valencia, 2018 [11])

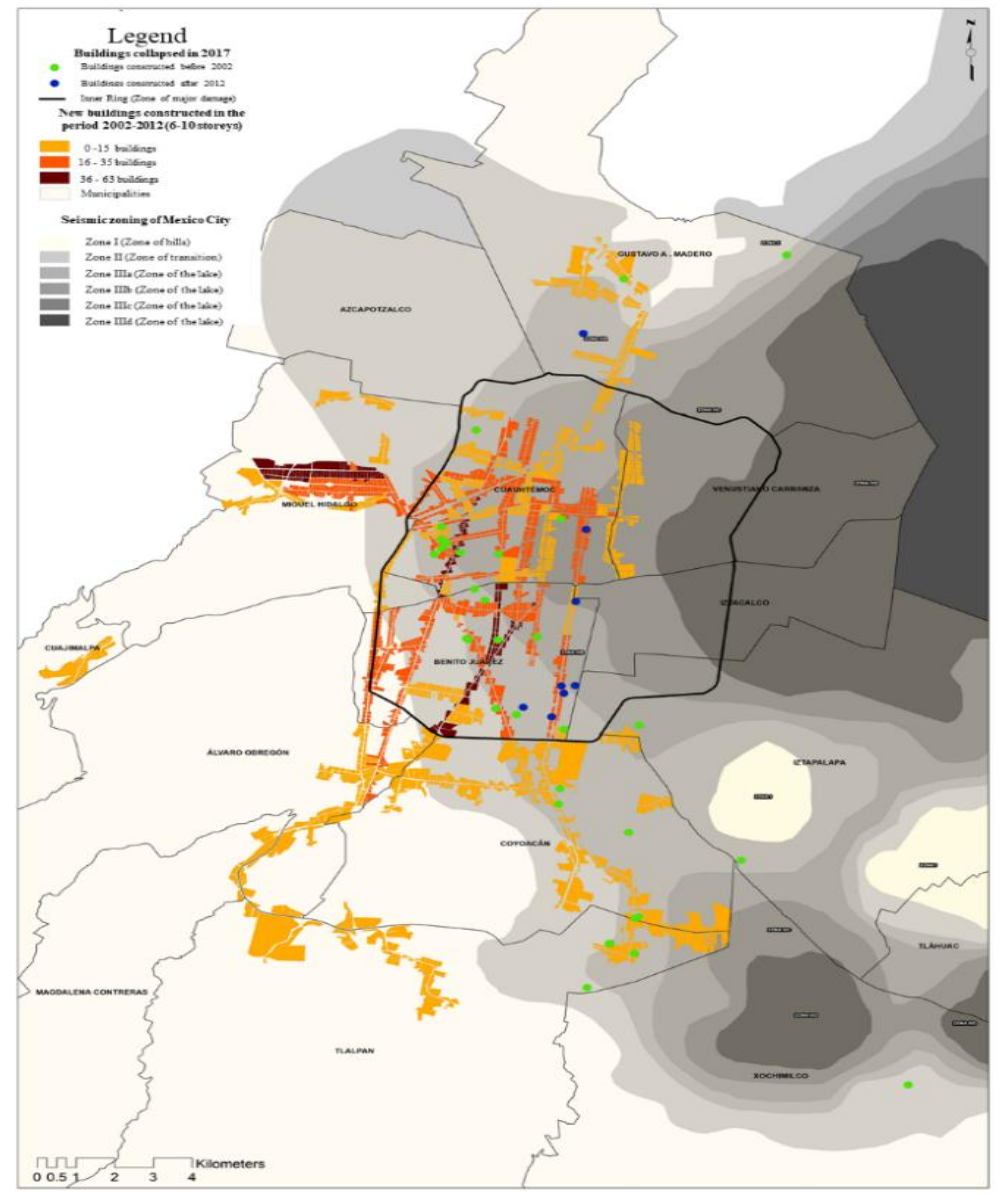

Figure 5. Verticalization on urban corridors for buildings between 6 and 10 storeys in Mexico City, 2002-2012. (Source: Field survey for 2002 and official sources for 2012) 


\subsection{Increase in density in old areas of Mexico City with insufficient infrastructure}

As the oldest part of Mexico City, we can refer to the Historical Center, the entire colonial part of the city of the sixteenth century, but also its first territorial extensions of the late nineteenth and early twentieth century. These are urban spaces to a greater or lesser extent planned with different timespace schemes ranging from large palaces and mansions to the first modern buildings, from carts to trains, and from trams to cars.

But the oldest parts of the city did not foresee an outward and upward future, however these were marked by economic activities and services, where an increase in the number of buildings from 6 to 10 levels is observed (see Figure 5, in orange and brown). That is, in the central part of the City in the Cuauhtemoc and Benito Juárez Municipalities, which traditionally concentrate the strongest economic, political and cultural activity of the city and which are an attraction for companies and therefore have a high demand for housing for those who work there.

Towards the beginning of the 21 st century, the challenge of this fascination for centrality, in addition to the increase in housing and office buildings, had as a consequence that the central zones began to be densified, their heights increased and the dynamics of growth accelerated. This had some consequences that were not planned but that were quickly corrected. That was the case of the transport infrastructure.

Consequently, the city was redesigned by implementing transportation models that were adopted as an example of other countries, particularly from Colombia (with the Transmilenio), which in Mexico was implemented as the Bus Rapid Transit ("Metrobus") transportation system. This system was introduced in those places that presented disorder and insufficiency of transport networks, planning this model to complement the metro public transport system and another new train system from the center to the periphery of the metropolis reducing travel times: the suburban train.

But not only transport networks have collapsed in Mexico City in the areas that have become densified and have grown vertically. Public works have been carried out to adapt and grow the drainage system and, in parallel, the water supply has had to be increased because now the housing areas are being transformed into apartment areas. In a place where on average lived between two and eight people, now live more than one hundred.

\subsection{Real estate speculation and verticalization as factors of segregation and fragmentation}

Towards the end of the 20th century in Mexico City, there was a model of a city in the process of deindustrialization, leaving spaces for abandonment due to the closure of some industries; at the same time, a major depopulated centrality was formed, partly due to the 1985 earthquake and also to the movement of the factories towards the periphery. However, towards the beginning of the 21 st century, urban public policies were contemplated to redensify the city with social housing such as Bando 2 (norm suspended in 2007) or Norm 26 (norm suspended in 2013). However, the real estate speculation was present in these processes creating new areas with densities above the norms, which gave way to the creation of new urban corridors as is the case of "Las Granadas", near Polanco, whose promoters even used the popularity of this neighborhood for the sale ("Nuevo Polanco").

The reconfiguration of this area took place from 2001 onwards, with its highest vertical growth point after 2008, with high-rise apartment buildings of 22 and 37 storeys with shopping centers, where more than 16 construction companies formed the new corridors Lago Zurich Avenue and the corridor Cervantes Saavedra Avenue (see Figure 6).
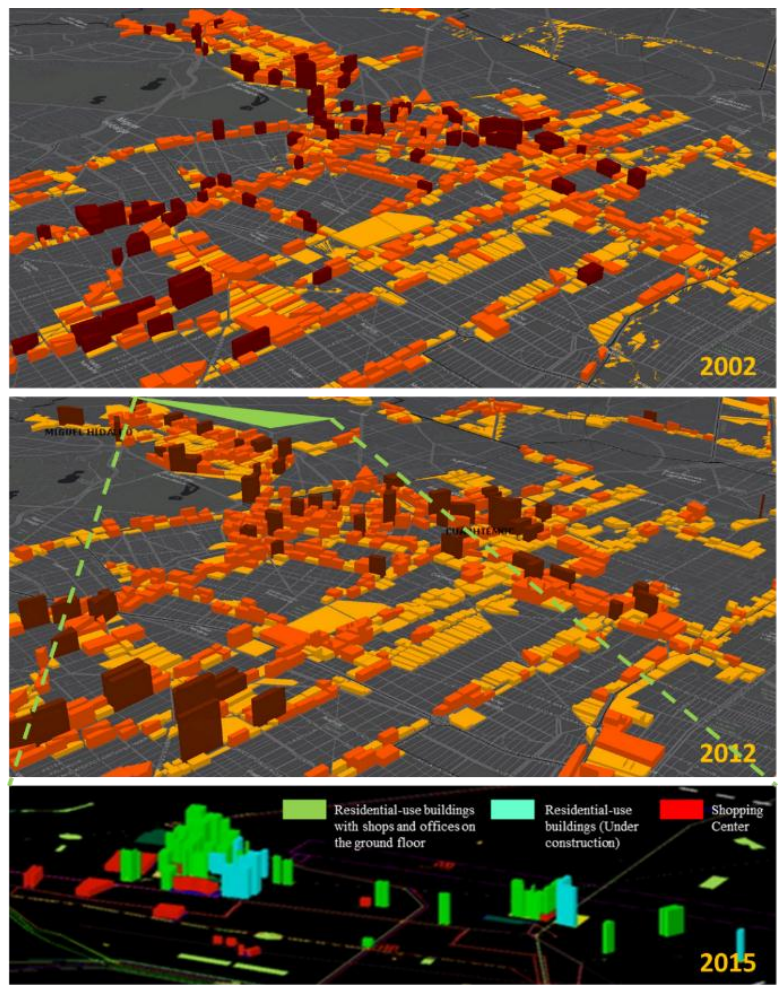

Figure 6. Three-dimensional model of verticalización for the period 2002-2012 on urban corridors in Mexico City (top) and the emergence of new urban corridors (bottom). (Source:

Field survey for 2002 and official sources for 2012)

However, it should be mentioned that the use of land allowed in this place permits heights up to 10 levels. Unfortunately, these interventions provoked processes of fragmentation of the territory with adjacent neighborhoods, partly due to the existence of the main roads that became physical barriers, such as the Rio San Joaquín Avenue, which separates this new elite zone from the colonies of another socioeconomic level.

Likewise, in the process of transformation, some houses of the last century have been segregated because they have managed to resist urban transformation such as the Cerrada de Andrómaco street, a very particular case with informal housing that has been tried to be bought by real estate companies to build new buildings.

Due to the accelerated increase of housing in the area, other difficulties have arisen, such as: a) the increase in traffic due to the fact that the dimensions of the streets are not prepared for this density; b) the increase of commercial and services areas with the inclusion of offices and shopping centers, causing public transport to saturate this area during the rush hours; c) insufficient infrastructure (drainage, water, light) due to excess population and floating population, since a cultural zone and tourist attraction has also been developed with new museums; d) insufficient public spaces, since residual spaces had to be habilitated because no green areas and open spaces were planned in areas with high densification -which are 
essential for evacuation in case of emergency.

In addition to the above, verticality by itself is already a risk when carried out in vulnerable areas by the type of soil. The buildings also rise without meeting the regulations and legality of the soil.

\section{CONCLUSIONS}

Verticality in cities should be considered as a topic of study that covers different approaches, so that the desired effects have an impact on the city and are not dissolved by limited approaches. It is hoped that with the densification of the city and its vertical growth there may be a decrease in travel, energy savings, a more organized mobility, travel reduction or a better use of urban land and infrastructure. However, if there is no a comprehensive and prospective study- in relation to other studies such as risk reduction, territorial planning, public policies and mobility- the result of the implementation of redensification can have negative or undesirable effects, leading to economic losses when redesigning policies to try to compose what did not turn out well; for this reason, some conclusions are:

- For the city of Mexico, it is surprising the lack of studies concerning vertical urban growth, even with an exploratory intention. The reason for this may lie on the fact that there is a lack of -existing- and comparative information. Nevertheless,

- The study of verticality based on urban corridors may be a way of analyzing the impact on the areas of influence around the corridors, since these can be visualized as a form of structure of the city. Corridors may be also the areas to observe not only the main processes of the city, but also a mean to identify areas for potential development;

- There is an increase in the value of the land derived from real estate speculation that verticalizes the city, resulting in gentrification phenomena that segregate and fragment the territory, causing more displacement of low-income people, giving way to a new elite that changes uses and traditions over the territory with new cultural practices;

- Mapping of urban corridors gives an account of which are the zones that were verticalized or are in such a process, and such information may serve to draw the attention when urban plans are being formulated;

- The changes described have increased the construction of new urban elements such as shopping centers in densified areas, encouraging displacements for consumption and in some cases causing the disappearance of public spaces;

- There is an urgency of comparing verticalization areas with seismic zoning, since these studies could mitigate the risk and possible human losses;

- Finally, to complement the instruments related to vertical urban growth, it is important that the planning instruments are well designed so that corruption doesn't take place.

- To conclude, we may say that factors of disaster risk move from quantitative to qualitative fields. In this article we focused on qualitative aspects that give rise to questions such as the interplay between planning, disasters, policies and actors involved.

\section{ACKNOWLEDGMENT}

The authors of this paper would like to thank the anonymous reviewers for his valuable comments and suggestions of this manuscript. This article is a product of the research project IPN-SIP 20172147, "The Vertical Expansion of Mexico City", funded by the Secretaría de Investigación y Posgrado del Instituto Politécnico Nacional, México.

\section{REFERENCES}

[1] Montejano-Escamilla, J.A., Caudillo-Cos, C.A. (eds) (2017). Densidad, Diversidad y Policentrismo: ¿planeando ciudades más sustentables? Centro de Investigación en Geografía y Geomática "Ing. Jorge L. Tamayo", A.C., Ciudad de México, México.

[2] Comisión Nacional de Vivienda. (2010). Guía para la Redensificación Habitacional en la Ciudad Interior. Gobierno Federal, SEDESOL, CONAVI, México, D.F https://www.gob.mx/cms/uploads/attachment/file/21489 4/Gui_a_para_la_Redensificacio_n.pdf accesed on Abr. 102019.

[3] Qin, J., Fang, C.L., Wang, Y., Li, G.D., Wang, S.J. (2015). Evaluation of three-dimensional urban expansion A case study of Yangzhou City, Jiangsu Province, China. Chinese Geographical Science, 25(2): 224-236. https://doi.org/10.1007/s11769-014-0728-8

[4] Shi, L.Y., Shao, G.F., Cui, S.H., Li, X.Q., Li, T., Yin, K., Zhao, J.Z. (2009). Urban three-dimensional expansion and its driving forces - A case study of Shanghai, China. Chin. Geogra. Sci., 19(4): 291-298. https://doi.org/10.1007/s11769-009-0291-x

[5] Qiao, W.F., Wang, Y.H., Ji, Q.Q., Ge, D.Z., Cao, M. (2019). Analysis of the evolution of urban threedimensional morphology: The case of Nanjing city, China. Journal of Maps, 15(1): 30-38. https://doi.org/10.1080/17445647.2019.1568922

[6] Salvati, L., Zitti, M., Sateriano, A. (2013). Changes in city vertical profile as an indicator of sprawl: Evidence from a Mediterranean urban region. Habitat International, 38: $119-125$ https://doi.org/10.1016/j.habitatint.2012.05.006

[7] Frenkel, A. (2004). Spatial distribution of high-rise buildings within urban areas: The case of the Tel Aviv Metropolitan Region. European Regional Science Association. ERSA Conference Papers.

[8] Vergara Vidal, J.E. (2017). Verticalización. La edificación en altura en la Región Metropolitana de Santiago (1990-2014). revista invi, 32(90): 9-49.

[9] DDF. (2001). Código Financiero del Distrito Federal. Editorial Sista. Distrito Federal, México. S 281.

[10] DDF. (1997). Manual Administrativo de la Subtesorería de Catastro y PadrónTerritorial de la Secretaría de Finanzas del Departamento del Distrito Federal. DDF. Distrito Federal, México, S 191.

[11] Valencia, M., Un negocio mortal: transformar una casa en departamentos, LNN Lanetanoticias. https://www.lanetanoticias.com/mi-edificio/307021/unnegocio-mortal-transformar-una-casa-en-departamentos, accessed on May 29, 2019. 